\title{
An economic evaluation of anticipated costs and savings of a behavior change intervention to enhance medication adherence
}

\author{
Phillip N. WIEGAND, Albert I. WERTHEIMER. \\ Received (first version): 14-Dec-2007 Accepted: 14-Mar-2008
}

\begin{abstract}
${ }^{*}$
Medication adherence across disease states is generally poor. Research has focused on various methods to improve medication adherence, but there is little conclusive evidence regarding specific methods efficacy. The Transtheoretical Model for Behavior Change has been used to modify existing addictive behaviors but not in medication adherence specifically. As a behavioral component is inherently related to medication adherence, it is thought that this model may be applicable.

Objective: The purpose of this research is to evaluate the costs and savings of implementing a novel behavioral intervention against the cost of poor medication adherence to determine whether further development is realistic.

Methods: The basic tools required to administer this intervention were determined through primary literature review and priced by vendors supplying such materials. Diabetes Mellitus Type 2 (DM2) was used as a vehicle to establish the cost of care for long-term complications of a chronic disease. The primary literature provided information regarding the cost of care for DM2 morbidity and outpatient annual drug therapy expenditure. The total cost of the behavioral intervention components and the cost of care for DM2 morbidity were applied to a theoretical cohort of 1000 patients. By dividing this cost across 1000 patients, a per-patient cost was yielded and multiplied over a 16-year timeframe. Results: It was found that the cost to implement the behavioral intervention and resultant medication costs is USD13,574 per-patient over 16 years. The cost to treat complications of diabetes mellitus is USD 36,528 per patient over the 16 years. The total amount of healthcare dollars potentially saved by utilizing this intervention is USD 22,954 per-patient. Conclusions: It appears that the cost to implement this behavioral intervention is reasonable and permits further evaluation in other chronic conditions with notoriously poor adherence levels.
\end{abstract}

Keywords: Costs and Cost Analysis. Patient Compliance. Models, Psychological. United Estates.

\footnotetext{
*Phillip N. WIEGAND, B.Sc., Pharm.D Candidate; Temple University School of Pharmacy, Philadelphia (USA). Albert I. WERTHEIMER, M.B.A., Ph.D Director, The Center for Pharmaceuticals Health Research. Temple University School of Pharmacy, Philadelphia (USA).
}

\author{
EVALUACIÓN ECONÓMICA DE COSTES \\ ANTICIPADOS Y AHORROS DE UNA \\ INTERVENCIÓN DE CAMBIO DE \\ ACTUACIÓN PARA MEJORAR LA \\ ADHESIÓN A LA MEDICACIÓN
}

\section{RESUMEN}

La adhesión a la medicación es generalmente pobre en las diferentes enfermedades. La investigación se ha centrado en diferentes métodos para mejorar la adhesión a la medicación, pero hay poca evidencia concluyente en cuanto a la eficacia de estos métodos. El Modelo Trans-teórico para el cambio de actuación se ha utilizado para modificar actuaciones adictivas, pero no específicamente en la adhesión a la medicación. Como un componente actuacional está inherentemente relacionado con la adhesión a la medicación, se piensa que este modelo puede ser aplicable.

Objetivo: El propósito de esta investigación es evaluar los costes y ahorros de la implantación de una intervención novedosa contra el coste de la mala adhesión a la medicación, para determinar si sería realista un desarrollo posterior.

Métodos: Se determinaron las herramientas básicas para administrar esta intervención mediante una revisión de la literatura y se calculó el precio de esos materiales según sus vendedores. Se utilizó la diabetes mellitus tipo 2 como vehículo para establecer el coste del tratamiento para las complicaciones a largo plazo de una enfermedad crónica. La literatura primaria proporcionó información sobre el coste de la atención para la morbilidad de la diabetes 2 y los gastos de medicación de los pacientes ambulatorios. El coste total de los componentes de la intervención actuacional y el coste de la asistencia de la morbilidad de la diabetes 2 se aplicaron a una cohorte teórica de 1000 pacientes. Dividiendo el coste total entre los 1000 pacientes, se obtuvo un coste por paciente que se multiplicó por un periodo de 16 años.

Resultados: Se vio que el coste de implantar una intervención actuacional y los costes consecuentes de medicación son de 13.574 USD por paciente durante un periodo de 16 años. El coste de tratar las complicaciones de la diabetes es de 36.528 USD por paciente durante esos 16 años.. La cantidad de dólares de sanidad potencialmente ahorrados al utilizar esta intervención es de 22.954 USD por paciente.

Conclusiones: Parece que el coste de implantar esta intervención actuacional es razonable y permite una 
evaluación posterior en otras enfermedades crónicas con notable poca adhesión al tratamiento.

Palabras clave: Costes y análisis de costes. Cumplimiento. Modelos Psicológicos. Estados Unidos.

\section{INTRODUCTION}

Medication adherence across disease states is not optimal. For example, in the management of Diabetes Mellitus Type 2 (DM2), 39\% to $93 \%$ of patients adhere to oral hypoglycemic agent therapy. ${ }^{1} \mathrm{HgBA} 1 \mathrm{C}$ measurements falling outside the American Diabetes Association guideline target range indicate that insulin self-management (injection compliance) is inadequate to maintain glycemic control. $^{2}$ Even in cancer, where significant morbidity and mortality is common, only $47 \%$ to $75 \%$ of patients comply with their medication regimen. $^{3}$

Researchers acknowledge this deficit and have focused their efforts on both behavioral and educational methods to improve medication adherence. Unfortunately, reviews of individual and combined methods aimed at targeting diseasespecific adherence challenges generally show limited efficacy.

Haynes et al compared intensive counseling technique or client-provider intervention (group motivation, structured, peer, or multi-component counseling; and intensive reminders of appointments) versus routine family planning counseling to improve hormonal contraceptive adherence. Of those studies reviewed, only one showed any improvement in patient adherence leading the authors to conclude that most studies to date have shown no benefit from strategies to improve adherence in this population. ${ }^{4}$

In DM2, Vermeire et al performed a meta-analysis on 21 studies assessing interventions aimed at improving adherence to treatment recommendations in people living with DM2 in primary care, outpatient settings, community and hospital settings. The studies evaluated nurse led interventions, home aides, diabetes education, pharmacy led interventions, and adaptation of dosing and frequency of a medication regimen. The authors concluded that current efforts to improve or to facilitate adherence of people with type 2 diabetes to treatment recommendations do not show significant effects or harms. ${ }^{5}$

In hyperlipidemia, Schedlbauer et al focused on assessing the impact of interventions to improve adherence to lipid-lowering medications. The eight studies meeting their inclusion criteria contained four categories of interventions: 1. simplification of drug regimen, 2. patient information/education, 3. intensified patient care such as reminding and 4 . complex behavioral interventions such as group sessions. In contrast to the above reviews, significant improvements in adherence were shown by simplifying the drug regimen, improving patient information/education and patient reminders. These improvements were evenly spread across each of these interventions, which led the authors to conclude that one intervention does not show a particular advantage over another. ${ }^{6}$

Schroeder et al reviewed methods to improve medication adherence in the treatment of hypertension. Of the 58 different interventions reviewed, dosing simplification, motivational strategies, complex interventions that involved more than one technique and patient education were the most prominent interventions employed. Although the authors concluded that regimen simplification should be the first line strategy, only $8 \%$ relative adherence improvement was observed across 7 studies. Patient education alone was largely unsuccessful, while complex and motivational strategies showed promise, although more carefully designed randomized controlled trials are needed to assess their efficacy. ${ }^{7}$

Research to improve medication adherence in the treatment of HIV/AIDS has shown similar outcomes to the above reviews. Rueda et al reviewed literature on the effectiveness of patient support and education to improve adherence to a common AIDS medication regimen. Of the 19 studies meeting their inclusion criteria, $52 \%$ demonstrated an improvement in medication adherence. Study interventions included cognitive behavioral therapy, motivational interviewing, medication management strategies, and interventions indirectly targeting adherence, such as programs directed to reduce risky sexual behaviors. Study heterogeneity prohibited a meta-analysis that specifically looked at outcomes. ${ }^{8}$ The efficacy of motivation interviewing in antiretroviral therapy was reviewed and did not show a significant increase nor decrease in percentage of dosages taken in a given month. Maximum adherence levels ranged from $49 \%$ to $93 \%$ in those receiving motivation interviewing. ${ }^{9}$ Educational and counseling efforts were no more effective than the standard of care in adherence to antiretroviral therapy as indicated by similar proportions of patients with serum HIV RNA $<40$ copies / mL. ${ }^{10}$ This review also showed that this intervention produced a $75 \%$ adherent population.

Across disease states, it appears that some approaches to medication adherence may improve the adherence level from baseline, but do not produce optimal results overall. Challenges to adherence research, such as study heterogeneity, small sample size, patients lost to follow-up and inconsistent methodology, make it difficult to truly assess the efficacy of promising interventions and thus possible application of an intervention. Regardless of the method or disease state, researchers recognize the need for future research to further explore and validate novel methods that have the potential to improve medication adherence. ${ }^{4,5,7,9}$

There is a behavioral component connected to routinely taking a medication. Although not applied specifically to medication adherence, Prochaska, 
has used the Transtheorectical Model for Behavior Change (TTM) to modify a number of health behaviors. The TTM has successfully been used to alter addictive behaviors related to smoking cessation $^{11-15}$ and also to promote healthy behaviors such as increased blood glucose monitoring and improved diet in diabetes ${ }^{16,17}$; regular exercise in overweight populations ${ }^{18}$; and avoiding unsafe sun exposure and receiving regular mammograms. ${ }^{14}$ This intervention has shown repeated efficacy in modulating risky health behaviors, which makes its application in improving medication adherence conceivable.

The application of the TTM is generally similar across the primary literature. ${ }^{19}$ The patients must initially complete a questionnaire that serves as the basis for tailoring this intervention to the subject. For example, in the process of smoking cessation, 7 measures were used to assess individual readiness to change to capture the smoker's level of confidence that he or she would not smoke in 20 challenging situations; how unpredictable, uncontrollable, and overloaded respondents find their lives; the physical dependence on nicotine; pros and cons of not smoking; how frequently the subject utilizes the 10 processes of change from the TTM; demographic data; and smoking social and family history. ${ }^{1}$ All of the questionnaires are delivered on reproduced, machine-readable forms or using a computer assisted telephone interview system (CATI).

In smoking cessation, the intervention consists of transtheoretical manuals and individualized written feedback. Counselors are also provided these patient-specific reports manuals and initiate a series of four personalized counselor calls at pretest, posttest, 3 months, 6 months, and possibly 12 months. All interventions were done by mail or phone contact or both. ${ }^{12}$

The transtheoretical manual is a 5-section report provided to the patient; one manual is provided for each behavior being modified. First, the patient's "stage of change" and readiness to change the behavior are reported. There are 5 stages of change in which the patient may fall, based on their readiness to change: Precontemplation, Contemplation, Preparation, Action, and Maintenance. These stages are used to gauge the subject's progress towards behavior change. ${ }^{20,21}$ The pros and cons of changing the behavior are then discussed. Next, feedback is given regarding the usage of up to 6 change processes relevant to their stage of change. The fourth section provides suggestions on how to improve self-efficacy in situations that tempt the patient to commit the behavior. The last section contains strategies for taking small steps to progress to the next stage of change. Typically, there is also a self-help manual associated with the questionnaires where the patients are referred for additional tips. ${ }^{14}$ The goal of the intervention is to progress each patient to take appropriate action, prevent relapse, and ultimately develop maintenance behaviors that sustain the desired health outcome. ${ }^{12-14}$
A major concern with adapting this intervention to medication adherence is whether the cost to implement the program would prohibit further development in healthcare. The purpose of this research is to evaluate the theoretical costs and potential savings of implementing a novel behavioral intervention against the cost of poor medication adherence to determine whether further development is realistic.

\section{METHODS}

This research was designed as a preliminary investigation to determine whether the costs and savings of implementing this behavioral intervention would permit further development in healthcare as a potential medication adherence intervention. We focused on determining the cost to implement the behavioral intervention, the cost of poor medication adherence in a chronic disease state. An assessment of those costs applied to a theoretical cohort of 1000 patients was made to ascertain if intervention implementation would save healthcare dollars in the form of avoided costs associated with the treatment of end-stage health complications in a chronic disease state.

The method to establish the cost of the behavioral intervention involved multiple steps. First, the primary and secondary literature was reviewed to outline the necessary materials to implement the behavioral intervention. The book "Interventions for Smokers: An International Perspective" contains information that explains how the intervention was administered. This book described the required patient interview forms used to assess the patient's readiness to change behavior, along with the hardware and software used to interpret and apply this information. Next, vendors were contacted to help determine a cost for these materials. Intangible items such as the cost of staff training and general utilities were ignored. It was assumed that if the intervention was successful, another associated cost was that of increased outpatient drug costs. This information was available in the primary literature. $^{19}$

The cost of poor medication adherence in a chronic disease state over time was evaluated using diabetes mellitus type 2 (DM2). This disease state was chosen as a vehicle to assess this cost because data exists regarding the distal outcomes of long-term inadequate disease control associated with disease progression over time. ${ }^{22-25}$ It was assumed that poor medication adherence, and thus disease control, resulted in development of additional morbidities over time. The incidence and cost to manage these additional morbidities were derived from Morsanutto et al. ${ }^{22}$ These costs included hospitalizations, physician visits, diagnostics and drug therapy to treat retinopathies, cardiopathies, vasculopathies, and nephropathies. It should be noted that this research is not suggesting the application of this behavioral intervention in DM2 medication adherence, as previous research does not support this use. 
Once the cost of implementing this behavioral intervention and that of poor medication adherence were individually determined, they were then compared on a per-patient basis over time to assess if healthcare dollars could theoretically be saved. First, a cohort of 1000 patients was assumed. The percentage of these patients with 1 or 2-plus complications and their respective annual costs were extracted from Morsanutto et al. ${ }^{22}$ and applied to this cohort. The annual cost was divided by 1000 to yield an average annual cost per patient. Similarly, the total cost of the behavioral intervention was divided across the cohort to yield an annual, per-patient cost. It was assumed that all patients contracting DM2 would have the disease by age 60 . With an average life-expectancy of 76 years, the patient would either pay for treatment of comorbidities or the behavioral intervention over 16 years. Accordingly, the annual cost of diabetic morbidities and the behavioral intervention were multiplied across this time frame to yield total perpatient cost figures.

The per-patient costs were subtracted from one another to produce a figure that represents the monetary savings afforded by utilizing the behavioral intervention.

\section{RESULTS}

The results of this study include the cost to implement the behavioral intervention; the cost of poor adherence in DM2; and a comparison of the costs and savings associated with implementation of the former vs. the latter.

Upon review of the primary and secondary literature describing the behavioral intervention, 13 components were identified. These components along with their associated costs are described in Table 1. The total cost to implement the intervention, annual per-patient cost and the perpatient cost over 16 years are: USD 29,410; USD 29.41; USD 470.56. Rathmann et al. ${ }^{23}$ describe the annual cost of outpatient drug therapy for DM2 as USD 819. Across 16 years, DM2 patient may expect to pay USD 13,104 for their medications. The combined total cost for the behavioral intervention and associated outpatient drug therapy over 16 years is USD 13,574.

Table 1: The Transtheoretical Model for Behavior Change System Components and Cost

\begin{tabular}{|l|r|}
\hline \multicolumn{1}{|c|}{ System Components } & Cost (USD) \\
\hline Survey Design & 125 \\
\hline Survey Printing & 450 \\
\hline Labor input - for scanning & 120 \\
\hline Software to interpret and generate output & 5,000 \\
\hline Stat / STS software & 365 \\
\hline Bitstream Frontware & 200 \\
\hline Specific Report & 100 \\
\hline Specific manuals & 750 \\
\hline CATI system & 17,000 \\
\hline CATI interviewing station & 1,000 \\
\hline CATI training & 3,000 \\
\hline Mailing costs & 1,000 \\
\hline Utility costs Total & 300 \\
\hline \multicolumn{2}{|c|}{ Total, Per-Patient } \\
\hline
\end{tabular}

Morsanutto et al. $^{22}$ perfomed a retrospective, longitudinal cost-of-care study of diabetic patients in Italy. In this population, $39.1 \%$ of patients had 1 complication and $27.1 \%$ of patients had 2 or more complications. The annual cost for the former and latter subgroups was USD 2,649.24 and USD $4,602.34$, respectively. Applied to this cohort, the total annual cost, the annual per-patient cost and the per-patient cost over 16 years are: USD 2,283,086; USD 2,283; and USD 36,528, respectively.

Based on these totals, the healthcare savings generated by implementing this behavioral intervention is USD 22,954 per-patient. A detailed description of the steps taken to generate these totals is outlined in Table 2.

\section{DISCUSSION}

Based on these results, the possible savings afforded by implementing the behavioral intervention vs. the cost of poor medication adherence may permit further investigation of this behavioral intervention in improving medication adherence. There are interesting similarities and differences between this behavioral intervention and the methods currently employed in improving medication adherence; these characteristics may be interpreted as both positive and negative features when assessing the value of this intervention.

On the intervention side of this behavior change method, the processes used to change behavior (i.e. patient education using intervention manuals, counseling sessions, structured follow-up etc.) are not much different than what is already used in medication adherence. The strength of the behavioral intervention lies in its ability to match an effective intervention to the patient's readiness to change their behavior. What works for one patient, may not work for another; thus, the ability to gauge fundamental differences between patients and, consequently, which methods may elicit a behavior change is valuable. Also, the primary literature seems to suggest that complex interventions that utilize multiple methods to improve medication adherence appear promising, but require further research. ${ }^{7}$ This observation also supports the use of this behavioral intervention, as multiple interventions are used to reach the desired outcome.

In theory, this behavioral method may appear as an answer to the current problems associated with improving medication adherence however; there are limitations to this model and the methods used in this study that could affect future development. Cost information is missing on both ends of the economic evaluation. The cost of poor medication adherence does not take into account all of the complications associated with disease progression and the cost of increased medication compliance on behalf of the patient. Quality of life and humanistic outcomes were also not factored into this study. 


\begin{tabular}{|c|c|}
\hline \multicolumn{2}{|c|}{ Table 2 Description of Calculations } \\
\hline \multicolumn{2}{|c|}{ Cost of Complications Related to DMII Patients with 1 complication (USD): } \\
\hline Per-patient total annual Cost: & $2,649.24$ \\
\hline Percentage of patients with 1 complication: & $39.1 \%$ \\
\hline $\begin{array}{l}\text { Number of patients from theoretical cohort with } 1 \\
\text { complication }\end{array}$ & 391 \\
\hline $\begin{array}{l}\text { Total annual cost for patients from theoretical cohort with } \\
1 \text { complication: }\end{array}$ & $2,649.24 * 391=1,035,852$ \\
\hline \multicolumn{2}{|c|}{ Cost of Complications Related to DMII Patients with 2 or more complications: } \\
\hline Total Annual Cost & $4,602.34$ \\
\hline Percentage of patients with 2 or more complications: & $27.1 \%$ \\
\hline $\begin{array}{l}\text { Number of patients from theoretical cohort with } 2 \text { or more } \\
\text { complications: }\end{array}$ & 271 \\
\hline $\begin{array}{l}\text { Total Annual Cost for patients from theoretical cohort } \\
\text { with } 2 \text { or more complications: }\end{array}$ & $4,602.34 * 271=1,247,234$ \\
\hline \multicolumn{2}{|l|}{ Combined costs for patients with 1 or 2 or more complications: } \\
\hline $\begin{array}{l}\text { Total Annual Cost for patients with } 1 \text { or } 2 \text { or more } \\
\text { complications: }\end{array}$ & $1,247,234.14+1,035,852.84=2,283,086$ \\
\hline Annual cost per-patient $(\mathrm{n}=1000)$ & 2,283 \\
\hline Cost per-patient over 16 years & $2,283 * 16=36,528$ \\
\hline \multicolumn{2}{|l|}{ Cost of the Behavioral Intervention } \\
\hline $\begin{array}{l}\text { Annual cost to implement the behavioral intervention and } \\
\text { outpatient medication cost }\end{array}$ & $29.41+819=848.41$ \\
\hline $\begin{array}{l}\text { Total cost to implement the behavioral intervention and } \\
\text { outpatient medication cost }\end{array}$ & $848.41 * 16=13,574$ \\
\hline \multicolumn{2}{|c|}{ Cost comparison of the behavioral intervention and complications related to diabetes mellitus type II } \\
\hline Cost Difference & $36,528-13,574=22,954$ \\
\hline
\end{tabular}

In order to produce the research results, assumptions were necessary to assess the cost of the behavioral intervention and the cost of poor medication adherence. Assumptions included: $100 \%$ medication and lifestyle adherence in those receiving the intervention; patients and counselors completed all aspects of the intervention; no patients were lost to follow-up; no patients developed the disease complications; the intervention described is the current and most efficacious model; all patients received the recommended treatment at the same cost; control of proximal outcomes of medication adherence if distal complications are avoided. Additionally, the literature provides more information regarding tangible inputs of the behavioral intervention and less on actual implementation requirements. The complete system can be found in the literature (citation) and compared against what was evaluated in this study. Thus, there may certainly be costs that were not assessed in this economic evaluation.

If all factors were appropriately assessed and it turned out that the cost to implement this intervention was excessive, one may argue that moving forward with the intervention is still the responsible and ethical course of action. Health policy that assures for continual support for these types of programs in the face of excessive cost is necessary, yet underdeveloped. Ultimately, instituting programs that help to assure long-term patient health is the responsibility of the healthcare community; however the drivers of this development are not clear.

In its current form, this research suggests that healthcare dollars may be saved if this behavioral intervention is used to improve medication adherence. Overall, current methods used to improve medication adherence are only marginally effective and do not produce optimal outcomes.
Although this intervention has not been used to improve medication adherence specifically, it appears effective in the populations where it has been applied and offers an advantage over current methods as specific interventions are aligned with a patient's readiness to change behavior.

The ability to gauge a patient's readiness to change a behavior, such as medication adherence, and coordinate interventions to help achieve this goal is the underlying benefit to this behavioral intervention. It is not to say that this intervention is necessarily the best and only method to reach this end; this particular behavioral intervention was evaluated because extensive research describing its delivery and efficacy exists. Overall, any novel method that can match efficacious interventions to an individual patient is highly valuable in improving healthy behaviors, such as routinely taking a medication. Compared against cost to manage the comorbidities associated with DM2, the cost to implement this intervention in its current form would not prohibit further development. Thus, this behavioral intervention, and others like it, should be evaluated for application in other chronic disease states with notoriously poor medication adherence.

\section{CONCLUSIONS}

The healthcare dollars saved by implementing this behavioral intervention based on the Transtheoretical Model for Behavior Change outweigh the cost to manage the morbidity associated with type 2 diabetes mellitus.

\section{CONFLICT OF INTEREST}

None declared. Authors declared have received no external funding to support this research. 


\section{References}

1. Cramer JA, Pugh MJ. The influence of insulin use on glycemic control: How well do adults follow prescriptions for insulin?. Diabetes Care. 2005 Jan;28(1):78-83.

2. Cramer JA.. A systematic review of adherence with medications for diabetes. Diabetes Care. 2004;27(5):1218-1224.

3. Ribeiro MJ. Compliance with guidelines for elderly patients undergoing cancer therapy. J Clin Oncology 2004;22(14S Supplement): 6148

4. Haynes RB, Yao X, Degani A, Kripalani S, Garg A, McDonald HP. Interventions to enhance medication adherence. Cochrane Database Syst Rev. 2005;(4):CD000011.

5. Vermeire E, Wens J, Van Royen $\mathrm{P}$, Biot $\mathrm{Y}$, Hearnshaw H, Lindenmeyer A. Interventions for improving adherence to treatment recommendations in people with type 2 diabetes mellitus. Cochrane Database Syst Rev. 2005;(2):CD003638.

6. Schedlbauer A, Schroeder K, Peters TJ, Fahey T. Interventions to improve adherence to lipid lowering medication. Cochrane Database Syst Rev. 2004;(4):CD004371.

7. Schroeder K, Fahey T, Ebrahim S. Interventions for improving adherence to treatment in patients with high blood pressure in ambulatory settings. Cochrane Database Syst Rev. 2004;(2):CD004804.

8. Rueda S, Park-Wyllie LY, Bayoumi AM, Tynan AM, Antoniou TA, Rourke SB, Glazier RH. Patient support and education for promoting adherence to highly active antiretroviral therapy for HIV/AIDS. Cochrane Database Syst Rev. 2006;3:CD001442.

9. Golin CE, Earp J, Tien HC, Stewart P, Porter C, Howie L. A 2-arm, randomized, controlled trial of a motivational interviewing-based intervention to improve adherence to antiretroviral therapy (ART) among patients failing or initiating ART. J Acquir Immune Defic Syndr. 2006;42(1):42-51.

10. Pradier C, Bentz L, Spire B, Tourette-Turgis C, Morin M, Souville M, Rebillon M, Fuzibet JG, Pesce A, Dellamonica P, Moatti JP. Efficacy of an educational and counseling intervention on adherence to highly active antiretroviral therapy: French prospective controlled study. HIV Clin Trials. 2003 Mar-Apr;4(2):121-31.

11. Fava JL, Velicer WF, Prochaska JO.. Applying the transtheoretical model to a representative sample of smokers. Addict Behav. 1995;20(2):189-203.

12. DiClemente CC, Prochaska JO, Fairhurst SK, Velicer WF, Velasquez MM, Rossi JS. The process of smoking cessation: an analysis of precontemplation, contemplation, and preparation stages of change. J Consult Clin Psychol. 1991;59(2):295-304.

13. Prochaska JO, DiClemente CC, Velicer WF, Rossi JS. Standardized, individualized, interactive, and personalized selfhelp programs for smoking cessation. Health Psychol. 1993;12(5):399-405.

14. Prochaska JO, Velicer WF, Redding C, Rossi JS, Goldstein M, DePue J, Greene GW, Rossi SR, Sun X, Fava JL, Laforge R, Rakowski W, Plummer BA. Stage-based expert systems to guide a population of primary care patients to quit smoking, eat healthier, prevent skin cancer, and receive regular mammograms. Prev Med. 2005;41(2):406-416.

15. Prochaska JO, Velicer WF, Rossi JS, Redding CA, Greene GW, Rossi SR, Sun X, Fava JL, Laforge R, Plummer BA. Multiple risk expert systems interventions: impact of simultaneous stage-matched expert system interventions for smoking, high-fat diet, and sun exposure in a population of parents. Health Psychol. 2004;23(5):503-516.

16. Vallis M, Ruggiero L, Greene G, Jones H, Zinman B, Rossi S, Edwards L, Rossi JS, Prochaska JO.. Stages of Change for Healthy Eating in Diabetes. Diabetes Care 2003;26:1468-1474.

17. Jones H, Edwards L, Vallis TM, Ruggiero L, Rossi SR, Rossi JS, Greene G, Prochaska JO, Zinman B; Diabetes Stages of Change (DiSC) Study. Changes in diabetes self-care behaviors make a difference in glycemic control: the Diabetes Stages of Change (DiSC) study. Diabetes Care. 2003;26(3):732-737

18. Sarkin JA, Johnson SS, Prochaska JO, Prochaska JM. Applying the transtheoretical model to regular moderate exercise in an overweight population: validation of a stages of change measure. Prev Med. 2001;33(5):462-469.

19. Velicer WF, Rossi JS, Ruggiero L, Prochaska JO. Minimal Interventions Appropriate for an Entire Population of Smokers. Interventions for Smokers: An International Perspective. Ed. Robyn Richmond. Baltimore: Williams \& Wilkins, 1994. 69-92.

20. Prochaska J. Stages of Change. Psychotherapy $2001 ; 38(4)$.

21. Prochaska JO.. Strong and weak principles for progressing from precontemplation to action on the basis of twelve problem behaviors. Health Psychol. 1994;13(1):47-51.

22. Morsanutto A, Berto P, Lopatriello S, Voinovich D, Gelisio R, Mantovani LG. Major diabetes complications have an impact on total annual medical cost of type 2 diabetes. Diabetes Care. 2004;27(7):1841-1842.

23. Rathmann W, Haastert B, Icks A, Giani G. Trends in outpatient prescription drug costs in diabetic patients in Germany, 1994-2004. Diabetes Care. 2007;30(4):848-853.

24. Caro JJ, Ward AJ, O'Brien JA. Lifetime costs of complications resulting from type 2 diabetes in the U.S. Diabetes Care. 2002;25(3):476-481

25. Brandle M, Zhou H, Smith BR, Marriott D, Burke R, Tabaei BP, Brown MB, Herman WH.. The direct medical cost of type 2 diabetes.. Diabetes Care. 2003;26(8):2300-2304. 